\title{
VRT liquid fertilizer applicator for soil nutrient management
}

\begin{abstract}
Graphical abstract Abstract Sensor based VRT liquid fertilizer application is a suitable way to apply the nutrients for soil management of various crops. Time and resources can be saved using this technology but due to the special characteristics of cereal and tree crops like paddy and oil palm, dedicated designs of VRT liquid fertilizer applicators are needed to fulfill the nutritional requirement of respective crops. The proposed design of VRT liquid fertilizer applicator involves soil fertility sensors, speed sensor, flow control valves, flow sensors and pressure sensor. Design considers the variable fertilizer flow compensation with change in forward speed of machine between $2.5-3.5 \mathrm{~km} / \mathrm{h}$. Also this design offers the transfer of data from electronic controller to the external computer for record and performance testing of machine by computing the lag times of flow control valves and application error of machine. Originally, the design is for tree crop; however, with a slight modification in controller's program, this will also be suitable for cereal crops like paddy. To apply the fertilizer, three DC pumps of 6.89 bar pressure and $5 \mathrm{~L} / \mathrm{min}$ flow rate were used in simulation with the flow lines of $6 \mathrm{~mm}$ internal diameter. Flow simulation revealed that the system was able to achieve the $0.06 \mathrm{~L} / \mathrm{s}$ at $13.73 \mathrm{~m} / \mathrm{s}$ velocity at nozzles 1 and 2 (full cone nozzles) while nozzles 3 and 4(flat fan nozzles) were delivering the same flow rate but at a little high velocity of 13.94 $\mathrm{m} / \mathrm{s}$. A comparatively uniform distribution of fertilizer application may be achieved using flat fan nozzles.
\end{abstract}

Keyword: VRT (variable rate technology); Liquid fertilizer; Flow control valve; Flow control system; Soil fertility sensor; Soil nutrients 